\title{
ANALISIS FONOLOGI PADA ANAK DOWN SYNDROME USIA 10 TAHUN (STUDI KASUS) DAN IMPLIKASINYA TERHADAP KETERAMPILAN BERBICARA TEKS DESKRIPSI TEMATIK DI SLB
}

Kholifah Karismawati, Sintowati Rini Utami, N. Lia Marliana

1. Universitas Negeri Jakarta, Indonesia

2. Universitas Negeri Jakarta, Indonesia

3. Universitas Negeri Jakarta, Indonesia

kholifahk39@gmail.com; sintowati_riniutami@unj.ac.id; nliamarliana@unj.ac.id

Abstrak. Penelitian ini bertujuan untuk memperoleh informasi tentang bentuk-bentuk penyimpangan yang terdapat pada ujaran anak down syndrome usia 10 tahun serta implikasinya terhadap keterampilan berbicara teks deskripsi. Penelitian ini merupakan penelitian studi kasus kualitatif dengan metode deskriptif yang terdiri atas metode simak dan cakap. Fokus analisis penelitian ini adalah pola bunyi atau ujaran pada tuturan anak down syndrome usia 10 tahun. Hasil analisis data menunjukkan bahwa data dengan hasil yang paling tertinggi, yaitu terdapat pada penghilangan fonem (omisi) sebanyak 59\%. Penggantian fonem (substitusi) sebanyak 18\%, penambahan fonem (adisi) sebanyak14\%, dan ketidakteraturan berbahasa (distorsi) sebanyak 9\%. Penghilangan fonem menjadi pembahasan yang terbanyak, karena sebagai bentuk penyederhanaan fonem, anak tersebut mengujarkan bunyi-bunyi bahasa tidak hanya terjadi pada fonem saja, tetapi terjadi pada beberapa fonem dalam satu kata. Implikasi pada penelitian ini, terdapat pada materi teks deskripsi dengan pendekatan kontekstual pada kelas VI SLB KD 3.2 dan 4.2 serta dapat diimplikasikan bagi pembelajaran dalam bidang linguistik, khususnya di bidang fonologi, yang menyelidiki bunyi-bunyi bahasa menurut fungsinya, seperti menyelidiki sistem fonem dari suatu bahasa, menelaah tentang cara bunyi berproses ketika membentuk sebuah kata atau frasa.

Kata Kunci: analisis fonologi, bentuk penyimpangan bunyi-bunyi bahasa, teks deskripsi

Abstract. This study aims to obtain information about the forms of deviation found in the speech of children with Down syndrome aged 10 years and their implications for speaking skills in descriptive text. This research is qualitative case study research with a descriptive method consisting of listening and speaking methods. The focus of the analysis of this research is the pattern of sound or speech in the speech of children with Down syndrome aged 10 years. The results of data analysis showed that the data with the highest results, which was found in the omission of phonemes (omisi) as much as $59 \%$. Phoneme substitution (substitution) is $18 \%$, phoneme addition (addition) is 14\%, and language irregularity (distortion) is $9 \%$. The omission of phonemes became the most discussed, because as a form of phoneme simplification, the child said that language sounds did not only occur in phonemes, but also occurred in several phonemes in one word. The implications of this research are descriptive text material with a contextual approach in class VI SLB KD 3.2 and 4.2 , especially in the field of phonology, which investigates sounds. language sounds according to their function, such as investigating the phoneme system of a language, studying how sounds process when forming a word or phrase.

Keywords: phonological analysis, forms of deviation of language sounds, descriptive text 
Kholifah Karismawati, Sintowati Rini Utami, N. Lia Marliana

Analisis Fonologi pada Anak Down Syndrome Usia 10 Tahun (Studi Kasus) dan

Implikasinya Terhadap Keterampilan Berbicara Teks Deskripsi Tematik Di SLB

\section{PENDAHULUAN}

Bahasa dianggap alat paling sempurna dan mampu menyampaikan pikiran dan perasaan tentang hal-hal yang konkret dan abstrak. Ini karena bahasa adalah proses mengeluarkan pikiran dan perasaan (dari otak) secara lisan dalam bentuk kata atau kalimat. Proses mengeluarkan pikiran dan perasaan (dari otak) secara verbal dalam bentuk kata atau kalimat sangatlah kompleks karena membutuhkan berfungsinya berbagai organ yang mempengaruhi mekanisme berbicara, berpikir, atau mengubah pikiran menjadi kata-kata.

Kemampuan berbahasa seseorang berpengaruh pada pola pikir dan berkomunikasi, bahwa di antara bahasa, komunikasi, dan bicara, bicara merupakan hal paling sulit bagi anak-anak down syndrome (Kumin, 2001). Hal tersebut dikarenakan anak down syndrome memiliki kesulitan dalam berbicara yaitu dalam perbendaharaan kata-kata, kelemahan artikulasi, kebiasan berbicara dengan menggunakan kata-kata yang terpisah.

Anak down syndrome memiliki masalah dalam pengucapan (Rondal, 1998). Ketika diminta untuk meniru apa yang orang lain katakan, lebih sedikit kesalahan pengucapan yang terjadi daripada yang mereka buat secara spontan. Penyandang down syndrome memiliki IQ di bawah 70. Namun, kecerdasan dan keterampilan bahasa mereka sangat bervariasi. Baik anak-anak maupun orang dewasa, tingkat pemahaman bahasa penderita down syndrome masih sangat terlambat (tidak cukup atau tidak mungkin). Artinya, meskipun perkembangannya lambat, bahkan jika beberapa orang tidak dapat sepenuhnya mengembangkan kemampuannya seperti orang dewasa pada umumnya, proses pemerolehan bahasa serupa dengan urutan normal. Itu tergantung pada tingkat keparahan penyakitnya.

Anak down syndrome memiliki keterbatasan dalam mengujarkan bunyibunyi bahasa (Baihaqi, 2011). Jika anak down syndrome tidak mampu menggerakkan alat-alat bicara, maka fonem yang dihasilkan akan hilang atau mereka menggantinya dengan menggerakkan artikulator yang lain, misalnya dalam beberapa kasus mereka mengalami kesulitan dalam bunyi dorso velar /k,g,G/ yang melibatkan artikulator aktifnya pangkal lidah dengan artikulator pasifnya langitlangit lunak, dengan begitu bunyi yang dihasilkan kemudian adalah bunyi apico alveolar /t,d/ yang melibatkan artikulator aktifnya ujung lidah dengan artikulator pasifnya gigi atas atau mereka menggantinya dengan medio palatal /c,j/ yang melibatkan artikulator aktifnya tengah lidah dan artikulator pasifnya langit-langit keras atau bahkan bunyi-bunyi itu tidak keluar karena adanya hambatan pada alatalat bicara.

Kemampuan pengujaran anak down syndrome adalah rendah karena mereka hanya mampu mengujarkan pada tingkat kata atau suku kata, belum sampai pada taraf morfologi, sintaksis, atau wacana. Kemampuan pengujaran pada tingkat kata atau suku kata tersebut mempunyai banyak sekali penyimpangan fonologi sehingga bunyi-bunyi yang keluar dari mulut si anak menjadi tidak jelas dan dan orang yang mendengarnya tidak dapat memahaminya. Kompetensi fonologi anak down syndrome memperlihatkan pola-pola penyimpangan fonologi pada masing-masing anak adalah berbeda, tergantung pada tingkat intelegensinya, kemampuan motorik, dan lingkungan yang membawanya.

Dalam kajian linguistik, tata bahasa ditempatkan dalam system bahasa. Sistem internal bahasa tersusun menurut suatu pola (sistematis), dan bukan merupakan sebuah sistem tunggal karena terdiri dari subsistem atau sistem bawahan. Jenjang subsistem ini dalam linguistik dikenal dengan nama tataran linguistik atau tataran bahasa. (Achmad dalam Utami, 2017). Secara hierakhi diurutkan dari tataran fonologi, tataran morfologi, dan tataran sintaksis. Fonologi ialah bidang ilmu linguistik yang mengkaji sistem dan fungsi bunyi dalam sesuatu bahasa. Salah satu kajian fonologi yaitu mengenal pasti dan menguraikan proses-proses fonologi yang beroperasi dalam sistem nahu sesuatu bahasa (Zaharani dalam Marliana, 2004). Tataran fonologi terdiri dari fonetik dan fonemik.

Penyimpangan kompetensi fonologi yang terjadi pada anak penderita gangguan berbahasa, down syndrome diperkuat oleh data yang diperoleh Blumstein, bahwa tipetipe penyimpangan fonologi yang biasa muncul meliputi penggantian fonem (substitusi), penambahan fonem (adisi), penghilangan fonem (omisi), dan ketidakteraturan berbahasa (distorsi). Penyimpangan fonologis tersebut dapat membuat mereka kesulitan menghasilkan 
Kholifah Karismawati, Sintowati Rini Utami, N. Lia Marliana

Analisis Fonologi pada Anak Down Syndrome Usia 10 Tahun (Studi Kasus) dan

Implikasinya Terhadap Keterampilan Berbicara Teks Deskripsi Tematik Di SLB

fonem-fonem yang wajar dalam pengucapan orang normal (Sastra, 2005).

Kemampuan produksi suara anak down syndrome mencakup dua hal yaitu yang pertama adalah kemampuan menghasilkan vokal, dan yang kedua adalah kemampuan untuk menghasilkan konsonan. Kemampuan vokal dapat membuat vokal di atasnya secara akurat yaitu mewakili vokal [a], [i], [u], [], [e], [] dan [o]. Vokal [a], [i], [u], [], [e], [] dan [o] didasarkan pada alokasi dan suku kata terbuka dan tertutup. Dalam hal ini, kemampuan konsonan mencakup dua hal yaitu berisi konsonan [b], [c], [d], [g], [h], [j], [k], [1], [m], [n], [p], [q], [s], [t] dan [y] dan konsonan [r], [f], [v], [w], $[\mathrm{x}]$ dan [z]. Kebanyakan konsonan bisa diucapkan oleh anak down syndrome secara sempurna, hanya beberapa konsonan saja yang tidak dia bisa bicara (Baihaqi, 2011). Pembelajaran teks deskripsi di SLB, khususnya pada keterampilan berbicara dapat membantu peserta didik dalam melatih kepekaaan karena dengan mendeskripsikan isi teks deskripsi secara lisan, peserta didik dapat menjelaskan secara nyata suatu objek ataupun suasana tertentu. Selain itu, peserta didik dapat menjelaskan dan menceritakan kembali suatu objek atau benda secara konkret yang dapat diinformasikan kepada pembaca.

Implikasi pada pembelajaran teks deskripsi tematik di SLB menggunakan pendekatan kontekstual, terdapat pada KD 3.2 yaitu menggali informasi dari teks deskriptif sederhana mengenai topik bacaan (namanama hewan, benda-benda yang ada di sekitar dan mengikuti instruksi yang diberikan) dengan bantuan guru dalam bahasa Indonesia lisan dan tulisan untuk membantu pemahaman dan KD 4.2 yaitu menceritakan kembali isi teks deskripsi dari topik bacaan (nama-nama hewan, bendabenda yang ada di sekitar dan mengikuti instruksi yang diberikan) secara mandiri dalam bahasa Indonesia lisan dan tulis untuk membantu penyajian.

Selain itu, penelitian ini juga dapat diimplikasikan bagi pembelajaran dalam bidang linguistik, khususnya di bidang fonologi, yang menyelidiki bunyi-bunyi bahasa menurut fungsinya, seperti menyelidiki sistem fonem dari suatu bahasa, juga menelaah tentang cara bunyi berproses ketika ia membentuk sebuah kata atau frasa. Dengan demikian, penelitian ini membahas mengenai analisis fonologi pada anak down syndrome usia 10 tahun dan implikasinya pada keterampilan berbicara teks deskripsi dengan pendekatan kontekstual. Dengan harapan, penelitian ini dapat meningkatkan komunikasi verbal yang tentunya akan menentukan kemampuan belajar dan interaksi sosial anak tersebut serta dapat memberikan sumbangan pemikiran ilmiah bagi perkembangan linguistik, khususnya pada bidang fonologi anak-anak yang mengalami hambatan dalam berbahasa.

\section{METODE PENELITIAN}

Metode yang digunakan dalam penelitian ini adalah metode kualitatif interaktif studi kasus yang terdiri atas metode simak dan cakap yaitu dengan menganalisis bunyi-bunyi yang diujarkan oleh anak down syndrome usia 10 tahun. Penelitian ini difokuskan untuk memperoleh informasi mengenai penyimpangan bunyi bahasa yang diujarkan oleh anak down syndrome usia 10 tahun. Penyimpangan bunyi bahasa yang dimaksud adalah 1) Penggantian fonem (substitusi), 2) Penambahan fonem (adisi), 3) Penghilangan fonem (omisi), dan 4) Ketidakteraturan berbahasa (distorsi).

Teknik analisis data dalam penelitian ini menggunakan teori Miles \& Huberman (1992). Pertama, dilakukan pengumpulan data, langkah-langkahnya adalah setelah mengambil data dari hasil mendeskripsikan, menganalisis lalu mengelompokkan data berdasarkan bentuk penyimpangan bunyi-bunyi bahasa yang diujarkan (subtitusi, adisi, omisi, dan distorsi). Kedua, melakukan analisis data untuk mengetahui bentuk penyimpangan bunyi-bunyi bahasa yang diujarkan (subtitusi, adisi, omisi, dan distorsi). Hasil yang telah dianalisis akan dimasukkan ke dalam tabel analisis kerja. Setelah analisis data, langkah selanjutnya adalah melakukan interpretasi data berdasarkan bentuk penyimpangan bunyi-bunyi bahasa yang diujarkan (subtitusi, adisi, omisi, dan distorsi). Dan langkah terakhir yaitu menarik kesimpulan berdasarkan interpretasi data penelitian, yaitu berdasarkan data yang paling tinggi atau tingkat kemunculannya paling mendominasi, hingga data yang paling rendah nilainya. Setelah itu, data dirangkum dan diinterpretasi. Selanjutnya, dilakukan pembahasan dari hasil interpretasi dan menyimpulkan hasil interpretasi. Dengan demikian, penelitian ini dapat mengetahui bentuk penyimpangan bunyi- 
Kholifah Karismawati, Sintowati Rini Utami, N. Lia Marliana

Analisis Fonologi pada Anak Down Syndrome Usia 10 Tahun (Studi Kasus) dan

Implikasinya Terhadap Keterampilan Berbicara Teks Deskripsi Tematik Di SLB

bunyi bahasa yang diujarkan oleh anak down syndrome usia 10 tahun.

\section{HASIL PENELITIAN}

Data dalam penelitian ini berupa ujaran bunyi-bunyi bahasa yang diujarkan oleh anak down syndrome usia 10 tahun. Data atau ujaran diperoleh dengan tanya jawab yang terdiri dari 3 topik cakapan yaitu menyebutkan nama-nama hewan yang ada di gambar, menyebutkan nama benda yang ada di sekitar, dan mengikuti instruksi yang diberikan oleh guru.

Tahap analisis data dimulai dari mengambil data dari hasil mendeskripsikan, menganalisis lalu mengelompokkan data berdasarkan bentuk penyimpangan bunyibunyi bahasa yang diujarkan (subtitusi, adisi, omisi, dan distorsi). Selanjutnya, melakukan analisis data untuk mengetahui bentuk penyimpangan bunyi-bunyi bahasa yang diujarkan (subtitusi, adisi, omisi, dan distorsi). Tahap selanjutnya, yaitu melakukan interpretasi data berdasarkan bentuk penyimpangan bunyi-bunyi bahasa yang diujarkan (subtitusi, adisi, omisi, dan distorsi). Terakhir, menarik kesimpulan yang menunjukkan data pada bentuk penyimpangan bunyi-bunyi bahasa yang diujarkan (subtitusi, adisi, omisi, dan distorsi).

Berdasarkan hasil analisis terhadap data yang diperoleh mengenai penyimpangan bunyi-bunyi bahasa yang diperkuat oleh teori dari Blumstein pada tahun 2005, bahwa tipe-tipe penyimpangan bunyi-bunyi bahasa yang biasa muncul pada penderita gangguan berbahasa itu meliputi penggantian fonem (substitusi), penambahan fonem (adisi), penghilangan fonem (omisi), dan ketidakteraturan berbahasa (distorsi).

Dari hasil analisis data yang dilakukan, ditemukan bentuk penyimpangan dalam bunyi-bunyi bahasa yang diujarkan oleh anak down syndrome usia 10 tahun yang meliputi penggantian fonem (substitusi), penambahan fonem (adisi), penghilangan fonem (omisi), dan ketidakteraturan berbahasa (distorsi). Dari keseluruhan data yang diperoleh, bentuk penyimpangan bunyi bahasa yang paling tinggi ialah pada penghilangan fonem (omisi) sebanyak 59\% dengan presentase fonem tertinggi pada /b/ dan /r/. Penggantian fonem (substitusi) sebanyak $18 \%$ dengan presentase fonem tertinggi pada $/ \mathrm{m} / \mathrm{dan} / \mathrm{g} /$, penambahan fonem (adisi) sebanyak $14 \%$ dengan presentase fonem tertinggi pada $/ \mathrm{n} /$, le/, dan /m/, dan yang terakhir adalah ketidakteraturan berbahasa (distorsi) sebanyak $9 \%$ dengan presentase fonem tertinggi pada $/ \mathrm{r} /$.

Temuan paling mendominasi dari bentuk penyimpangan bunyi-bunyi bahasa pada tuturan anak down syndrome usia 10 tahun yaitu pada penghilangan fonem (omisi). Penghilangan fonem menjadi pembahasan yang paling banyak, karena sebagai bentuk penyederhanaan fonem, anak tersebut mengujarkan bunyi-bunyi bahasa tidak hanya terjadi pada fonem saja tetapi juga kadang terjadi pada beberapa fonem dalam satu kata yang disebabkan oleh proses kontraksi atau penyingkatan yang digolongkan dalam proses sinkop karena penghilangan fonem terdapat di tengah kata. Selanjutnya, terdapat penggantian fonem (substitusi) dengan kehadiran terbanyak setelah penghilangan fonem (omisi), karena dalam mengujarkan bunyi-bunyi bahasa, anak tersebut kerap menggantikan fonem yang berbeda dengan fonem asli atau tujuan yang disebabkan karena adanya proses retrofleksi, yaitu proses penarikan ujung lidah melengkung ke arah langit-langit keras sewaktu artikulasi primer berlangsung dan proses palatalisasi, yaitu proses pengangkatan daun lidah ke arah langitlangit keras (palatum) sewaktu artikulator primer berlangsung.

Setelah itu, terdapat bentuk penyimpangan penambahan fonem (adisi), yang dimana dalam mengujarkan bunyibunyi bahasa, anak tersebut kerap menambahkan sebuah fonem di dalam ujarannya yang disebabkan karena pengaruh proses anaftiksis, yaitu proses penambahan bunyi vokal atau konsonan. Kata-kata tersebut termasuk dalam golongan epentesis karena proses penambahan bunyi berada di tengah kata.

Terakhir, bentuk penyimpangan bunyi bahasa yang kehadirannya menjadi paling rendah yaitu ketidakteraturan berbahasa (distorsi), karena perubahan pelafalan secara halus yang diujarkan oleh anak tersebut, kata yang diucapkan masih dapat dipahami namun pelafalannya tetap salah, atau tidak terdengar seperti kata yang terdapat dalam bahasa bersangkutan. Disebabkan oleh adanya proses disimilasi, yaitu proses perubahan dua bunyi yang sama menjadi dua bunyi yang berbeda atau tidak sama. 
Kholifah Karismawati, Sintowati Rini Utami, N. Lia Marliana

Analisis Fonologi pada Anak Down Syndrome Usia 10 Tahun (Studi Kasus) dan

Implikasinya Terhadap Keterampilan Berbicara Teks Deskripsi Tematik Di SLB

\section{SIMPULAN}

Berdasarkan hasil penelitian yang dilakukan, dapat disimpulkan bahwa penyimpangan bunyi fonetik dalam bidang fonologi, khususnya penyimpangan bunyibunyi bahasa yang dialami oleh anak down syndrome usia 10 tahun ini, terbagi ke dalam empat jenis, yaitu: penghilangan fonem (omisi) sebanyak 59\% dengan presentase fonem tertinggi pada /b/ dan /r/, penggantian fonem (substitusi) sebanyak $18 \%$ dengan presentase fonem tertinggi pada $/ \mathrm{m} /$ dan $/ \mathrm{g} /$, penambahan fonem (adisi) sebanyak $14 \%$ dengan presentase fonem tertinggi pada /n/, /e/, dan /m/, dan ketidakteraturan berbahasa (distorsi) sebanyak $9 \%$ dengan presentase fonem tertinggi pada $/ \mathrm{r} /$.

Penghilangan fonem (omisi) merupakan penyimpangan bunyi-bunyi bahasa yang terjadi akibat adanya penghilangan salah satu bunyi konsonan pada kata yang diucapkan, penghilangan tidak hanya terjadi pada fonem saja tetapi juga kadang terjadi pada beberapa fonem dalam satu kata. Penghilangan fonem juga disebabkan oleh proses kontraksi atau penyingkatan yang digolongkan dalam proses golongan apheresis, yaitu penghilangan fonem yang terdapat pada awal kata dan terdapat proses golongan sinkop karena penghilangan fonem terdapat di tengah kata.Penghilangan fonem (omisi) lebih banyak terjadi bila dibandingkan dengan penyimpangan bunyi-bunyi bahasa lainnya.

Hasil dari penelitian ini, dapat diimplikasikan bagi pembelajaran Bahasa Indonesia pada materi teks deskripsi dengan pendekatan kontekstual untuk kelas VI SDLB KD 3.2 dan KD 4.2. Pada KD tersebut, membahas mengenai informasi yang didapatkan dari teks deskriptif sederhana dari topik bacaan (nama-nama hewan, benda-benda yang ada di sekitar dan mengikuti instruksi yang diberikan) menggunakan pendekatan kontekstual. Namun, materi teks deskripsi KD 3.2 dan 4.2 ini tidak membahas mengenai struktur dan kaidah kebahasaannya, melainkan hanya untuk mengetahui pola ujaran dari jawaban siswa down syndrome usia 10 tahun ketika diberikan beberapa pertanyaan. Selain itu, penelitian ini juga dapat diimplikasikan bagi pembelajaran dalam bidang linguistik, khususnya di bidang fonologi, yang menyelidiki bunyi-bunyi bahasa menurut fungsinya, seperti menyelidiki sistem fonem dari suatu bahasa, juga menelaah tentang cara bunyi berproses ketika ia membentuk sebuah kata atau frasa. Penelitian ini memiliki beberapa keterbatasan yang perlu dikembangkan lebih lanjut. Diharapkan penelitian selanjutnya dapat mengembangkan analisis fonologi yang lebih memfokuskan ruang lingkup lainnya, serta dapat menerapkan pada materi pembelajaran Bahasa Indonesia yang meliputi struktur dan kebahasaan.

\section{SARAN} kepada:

Saran dalam penelitian ini ditujukan

a) Peneliti di bidang pendidikan, bahasa, dan sastra Indonesia. Penyimpangan bunyi fonetik pada anak down syndrome juga dapat dikaji dengan teori lainnya, misalnya dengan teori morfologi, semantik, sintaksis, dan lainnya. Selain itu, penelitian ini dapat dikembangkan lagi baik dari objek penelitiannya, jenis gangguan, ataupun metode penelitiannya.

b) Ahli Linguistik

Diharapkan agar ahli linguistik dapat mengembangkan ilmu fonologi (bunyi bahasa) berdasarkan pelafalan vokal dan konsonan yang diucapkan pada pasien yang menderita gangguan berbicara dan gangguan berbahasa lainnya.

\section{DAFTAR PUSTAKA}

Baihaqi, M. L. (2011). Phonological competence of children with down syndrome at SLB C Negeri 1.Yogyakarta. Widyariset, 14(1), 153-162.

Chaer, Abdul. (2003). Linguistik umum. Jakarta: PT Rineka Cipta.

Libby, Kumin. (2001). Speech intelligibility in individuals with Down syndrome: A framework for targeting specific factors for assessment and treatment. Down syndrome Quarterly.

Marliana, N. L., \& Phil, M. (2009). Perbezaan bunyi [a] dan [ə](schwa) dalam bahasa melayu bagi pelajar indonesia di malaysia: satu kajian fonologi. Komunikologi: Jurnal Ilmiah Ilmu Komunikasi, 6(1).

Muslich, M. (2008). Fonologi bahasa Indonesia: Tinjauan deskriptif sistem bunyi bahasa Indonesia. Bumi Aksara. 
Kholifah Karismawati, Sintowati Rini Utami, N. Lia Marliana

Analisis Fonologi pada Anak Down Syndrome Usia 10 Tahun (Studi Kasus) dan Implikasinya Terhadap Keterampilan Berbicara Teks Deskripsi Tematik Di SLB

Rondal, Jean A. (1998). Cases of exceptional language in mental retardation and Down syndrome: Explanatory perspectives. Down syndrome Research and Practice.

Sastra, G. (2005). Ekpresi verbal penderita strok dari sudut analisis neurolinguistic. Doctoral dissertation, Universiti Putra Malaysia.

Utami, S. R. (2017). Pembelajaran Aspek Tata Bahasa dalam Buku Pelajaran Bahasa Indonesia. Aksis: Jurnal Pendidikan Bahasa dan Sastra Indonesia, 1(2), 189-203. 